\title{
Assess Forgiveness of Syrian Refugee's Students in Jordan and Its Relation to Some Variables
}

\author{
Dr. Jehad Mohammed ALanati \\ Associated Professor of Educational Psychology .University of Jordan, Amman,Jordan \\ Dr. Omar Ismail ALorani \\ Dr of Counseling\& Special Education . University of Jordan, Amman ,Jordan
}

\begin{abstract}
Forgiveness is an important aspects of the grief process for many people, and related to events that occur in our life such as war. The purpose of this study was Assess forgiveness and its relation to some variables for Syrian Students refugees in Jordan within the context of a real-life transgression occurred with them. To achieve study purpose there was a sample consist of (193) Students in Ages (11-18) chosen randomly by Stratified Cluster method, and The researchers used Heartland Forgiveness Scale (HFS). This questionnaire consists of (18) items intended to elicit students' opinions about forgiveness using a (4) point Likert scale. They include three Subscales: Forgiveness of Self(items: 1-6), forgiveness of others(items: 7-12), Forgiveness of Situations (items: 13-18).The face validity and construct validity of Forgiveness Scale / Subscale was verified and it was good. The reliability of Forgiveness Scale was verified by Cranach's alpha coefficient and split half method to find internal consistency reliability and it is an acceptable values $(0.764),(0.721)$. The results showed that the level of forgiveness was moderate on (HFS) scale and Subscales, and its averages in descending order:Forgiveness of Self, Forgiveness of Situations, and Forgiveness of Others). There aren't statistically significant differences in (HFS) scale and Subscales: Self Forgiveness \& Situations Forgiveness due to student gender and his developmental stage, While differences in Forgiveness of Others statistically significant for males.
\end{abstract}

Keywords: adolescence ,society, war ,Forgiveness Scale, migration .

DOI: $10.7176 / \mathrm{JEP} / 11-9-06$

Publication date:March $31^{\text {st }} 2020$

\section{Introduction}

In this study UrieBronfenbrenner's theory of Bio-ecological model was used to explaining the contextual factors that appear to affect the Syrian Students refugee's characteristics in Jordan caused by war, specifically Forgiveness. The Bio-ecological model describes the role of the genetic make-up and the environment in determining human development throughout their entire life-span (Eggen and Kauchak, 2010).

According to the bio-ecological theory, children's development takes place through interaction between a set of properties and the environment to produce constancy and change in the character of a person over the course of life (McMillan, 1990). Development occurs across a number of human dimensions such as cognition, social competence and temperament.

Interaction is a dynamic, reciprocal, verbal and non-verbal exchange between an individual and other human beings and objects in the immediate environment (Bronfenbrenner, 1994). Such as Forgiveness it may occur between students with himself, students with other and students with situations.

According to Sontag (1996), an ecological niche is a special area in the environment which is particularly favorable or unfavorable to the development of persons with certain characteristics. The concept of an ecological niche implies a consideration of one's personal attributes and interactions with the environment which lead to the full realisation of the individual's potential. This theory is relevant to this study because it explains the influence of proximal as well as distant contextual factors in the development of the Syrian Students refugees in Jordan within the context of a real-life transgression occurred with them.

The bio-ecological theory gives a detailed explanation of the situation, possible causes, and explains how the solutions implemented in different contexts may benefit growing Syrian Students refugees in Jordan. The contextual factors of an individual are the microsystem, mesosystem, exosystem and the macrosystem. The contextual subsystems interact with four dimensions of the ecological model, namely: Processes, Person, Context and Time (PPCT (Araujo and Davids 2009; Rosa and Tudge 2013).

These subsystems have interactive relationships with individuals (Araujo and Davids, 2009; Rosa and Tudge, 2013). The first element of the model, the processes, indicates daily interactions with objects, symbols, and other individuals in which and with whom one is actively and consistently engaged (Rosa and Tudge, 2013).Processes are face to face interactions; this is why they are called proximal processes. Proximal processes involve a two-way movement of energy from an individual to the environment and back again, either sequentially or concurrently. This movement is said to be bi-directional because it moves to and fro. A sequential bi-directional movement emanates from an individual to the environment or vice versa and back while a concurrent movement moves 
simultaneously between an individual and the environment (Bronfenbrenner and Evans, 2000; Araujo and Davids, 2009; Tudge, Mokrova, Hatfield and Karnik, 2009).

Studies (Araujo and Davids, 2009; Tudgeet al., 2009) have established that proximal processes are a driving force of human development because it is through them that "genetic potentials for effective psychological functioning are actualized" (Bronfenbrenner and Cici, 1994:568). What a child can be is realized through the interaction with an environment. Such interaction ensures that a child is not passive but engages in activities that enable development (Araujo and Davids, 2009). A child actively shapes the environment by eliciting its reactions and responding to them (Darling, 2007). It is through this process that children comprehend the world and their place in it and then play their part by changing and fitting in it. As a result, children develop skills, knowledge and abilities that lead their behavior across situations (Rosa and Tudge, 2013). Another important aspect that individuals develop Forgiveness competence through these proximal processes, Forgiveness needs to demonstrate further development of knowledge, skill or ability to direct one's behavior across situations and developmental domains.

Forgiveness of other and self-forgiveness are important aspects of the grief process for many people. In the past, forgiveness had been limited to religious teaching and traditions, however in the last quarter of the 20th century, research among mental health practitioners focused on the mental health aspects of forgiveness and selfforgiveness. When assessing the biopsychosocial, spiritual aspects of clients it is important to assess the person's readiness to work on forgiveness of others and self-forgiveness.(George,2011)

It is not easy to find a single definition of forgiveness, (Worthington \&Wade ,1999.) to a distinction between forgiveness and unforgiveness: Unforgiveness is a cold emotion involving resentment, bitterness, and perhaps hatred, along with the motivational avoidance of the transgressor. Forgiveness is a victim's internal choice (unconscious or deliberate) to relinquishing forgiveness and to seek reconciliation with the offender.

Also Forgiveness define as a process (or the result of a process) that involves a change in emotion and attitude regarding an offender. Most scholars view this intentional and voluntary process, driven by a deliberate decision to forgive. This process results in decreased motivation to retaliate or maintain estrangement from an offender despite their actions, and requires letting go of negative emotions toward the offender (American Psychological Association, 2006).also forgiveness define as a skill that can be learned, and an opportunity to take control of the situation and reassert personal power(.Luskin ,2002.).

Forgiveness also related to events that occur in our life such as war, for example Syrians war affected totally to The contextual subsystems of Syrian Students refugees in Jordan (microsystem, mesosystem, exosystem and macro system) \& dimensions of the ecological model( Processes, Person, Context and Time).

According to the United Nations, the death reached 120,000 by September 2013 (Alliance News, 2013). As many as 3.6 million Syrians may be internally displaced, left their homes and are living somewhere inside Syria (Sharp \& Blanchard, 2013). In addition, international relief agencies estimated that was more than 1,380,406 Syrians fled the country. Of those more than 1.1 million had left since September 2012 to so-called safe areas outside the Syrian borders.

Jordan had 441,756 registered refugees. Over 80,000 refugees live in Zaatari refugee camp in Northern Jordan near the Mafraq Governorate according to United Nations High Commissioner for Refugees officials who run the camp. Life in refugee camps harsh with individuals and families living with uncertainty over their future and anxiety for any members of the family. The impact on children in terms of their future is of continuing concern occasioned by what they witnessed as well as by the insecurity of life in the camps.

War and conflict have damaging effects on children and their education (Al Zaroo\&Hundt,2003). This point is made by Evans, Garner, and Honig (2014 ) in their introductory chapter to this special issue. The grave consequences for children entail their very survival as well as their development. They may be killed, injured, imprisoned, abused, starved, humiliated and traumatized by direct negative experiences or indirectly by what happens to their parents, relatives and friends. The children may experience psychological problems, such as nightmares, panic attacks, self-withdrawal, aggressive behavior, insecurity and violence towards family members and friends. All of these psychological problems may affect forgiveness in Syrian refugee students (Affouneh,2007). Forgiveness is a free choice on the part of the one wronged, it can be unconditional regardless of what the offender does. This view holds that forgiveness should not be contingent on the offender's desire for reconciliation, because that would condemn the person who was wronged to the state of unforgiveness as long as the wrongdoer desired, vesting too much power in the offender. For these researchers, the offender's wish for reconciliation is not a prerequisite for forgiveness ( María \&Virginia , 2018)

In our study we will assess forgiveness of Syrian refugee's students in Jordan and its relation to some variables by answering the following questions:

1. What are the levels of forgiveness among Syrian refugee's students in Jordan?

2. Are there any statistically significant differences in forgiveness of Syrian refugee's students in Jordan that can be attributed to the student's gender and his developmental stages? 


\section{Methods}

Design and sample

\section{Sample of the Study}

The sample of this study consists of the Syrian Students refugees in (12) centers located in northern and middle of Jordan during the academic year 2018-2019. The sample randomly selected by Stratified method \&consist of (193)students in ages (12-17),table (1) shows the distribution of study sample (see table 1 )

\section{Measures}

The researchers used Heartland Forgiveness Scale (HFS) to develop Jordan copy questionnaire. This questionnaire consists of (18) items intended to elicit students' opinions about forgiveness using a (4) point Likert scale(Almost Always True of Me ,More Often True of Me, Almost Always False of Me, More Often False of Me). and it includes three Subscales. The first Subscale consisted of items (1-6) exploring Forgiveness of Self. The second Subscale consisted of items (7-12) aiming at students' opinions about forgiveness of others. The third Subscale consisted of items (13-18) exploring Forgiveness of Situations (Fernández\& Worthington, 2017).

Forgiveness Scale Scoring:

The scores for items: 1, 3, 5, 8, 10, 12, 14, 16, and 18 are (4: Almost Always True of Me ,3:More Often True of Me, 2:Almost Always False of Me, 1:More Often False of Me),but it in reverse order For items 2, 4, 6, 7, 9, 11, 13,15 , and 17 , Score as in the boxes below:

\begin{tabular}{|lc|c|c|c|c|}
\hline $\begin{array}{l}\text { Forgiveness Scale / } \\
\text { Subscale }\end{array}$ & $\begin{array}{c}\text { Forgiveness of } \\
\text { Self }\end{array}$ & $\begin{array}{c}\text { Forgiveness of } \\
\text { Others }\end{array}$ & $\begin{array}{c}\text { Forgiveness of } \\
\text { Situations }\end{array}$ & $\begin{array}{c}\text { Total } \\
\text { Forgiveness }\end{array}$ \\
\hline Score & $6-24$ & $6-24$ & $6-24$ & $18-72$ \\
\hline
\end{tabular}

\section{Interpretation Forgiveness Score:}

Score on the Self Forgiveness indicates how student tend to forgiving to himself. Similarly, score on the Forgiveness of Others reflects how student tend to forgiving to other people, and score on the Forgiveness of Situations shows how student tend to forgiving negative circumstances, events, or situations that are beyond anyone's control (such as a an illness or natural disaster). score on the Total Forgiveness scale indicates how student tend to forgiving in general with himself, others, and negative uncontrollable circumstances. The Interpretation of Subscale Scores Average and the Total Scale Score Average as in the boxes below

\begin{tabular}{|l|c|c|c|}
\hline Score Average & $1-2$ & $2.1-3$ & $3.1-4$ \\
\hline Interpretation of forgiveness & Lower levels & Medium levels & Higher levels \\
\hline
\end{tabular}

\section{Validity of Forgiveness Scale}

To verify the face validity of Forgiveness Scale / Subscale by given to a jury of (7) university professors and experts in Save the Children Society. the appropriateness of Forgiveness Scale for the Syrian refugee students is good. the agreement ratio(86-100)\% between jury are good. the experts' comments and suggests was used to prepare the final version of instrument (replacement of some vocabulary to become more appropriate to the local environment).

The construct validity of Forgiveness Scale was verified further by applying it on a different sample (pilot sample) than the intended group and finding Pearson correlation coefficient between item scores and Scale / Subscale scores (Forgiveness of Self, Forgiveness of Others, Forgiveness of Situations, and Total Forgiveness), and factor analysis. (See tables (2), and 3)

In table (3) the Forgiveness Scale measures one characteristic, where the value of the explained variance by first factor $(37,471)$ is more than twice the value explained by second factor. The total variance explained by the first three factors was approximately $70 \%$, which is high. Figure (1) confirms the results of the construction validity of Forgiveness Scale.

\section{4-Reliability of Forgiveness Scale}

The reliability of Forgiveness Scale was verified by Cranach's alpha coefficient split half method to find internal consistency reliability and it is an acceptable value.(See table 4).

The reliability of Forgiveness Scale was verified by Cranach's alpha coefficient split half method to find internal consistency reliability and it is an acceptable value.

\section{5-Statistical analysis}

Data will be analyzed using the SPSS statistical package using means, standard deviations, and analysis of variance ANOVA.

\section{Results}

This Part will include an overview of the findings and their analysis through answering study questions of forgiveness of Syrian refugee's students in Jordan.

\section{The results of the first question:}

What are the levels of forgiveness of Syrian refugee's students in Jordan?

In order to answer the question, averages and standard deviations of the sample were extracted on Forgiveness 
items, Subscale, Scale, and Table (5) shows the results.(see table 5).

Results in Table 5 indicate that the average of forgiveness is (2.514) with standard deviation (0.380), i.e., the level of forgiveness of Syrian refugee's students in Jordan is Medium. The forgiveness Subscales averages are very close: Forgiveness of Others (2.418), Forgiveness of Situations (2.436), Forgiveness of Self ( 2.685).

The levels for Forgiveness of Others is High on item 8 (With time I am understanding of others for the mistakes they've made).,but its Medium on items $(7,9,10,11,12)$. the levels for Forgiveness of Situations is Medium on items (13-18), and the levels for Forgiveness of Self is High on items 5, 3 (With time I am understanding of myself for mistakes I've made), ( Learning from bad things that I've done helps me get over them.), but its Medium on items $(1,2,4,6)$.

The results of the second question:

Are there any statistically significant differences in forgiveness of Syrian refugee's students in Jordan that can be attributed to the student's gender and his developmental stages, parent status and his educational level?

1. The results of the first hypothesis test: There will be no statistically significant differences $(\alpha=0.05)$ in forgiveness of Syrian refugee's students in Jordan that can be attributed to the student's gender.

In order to test the hypothesis, the averages and standard deviations of males and females groups were extracted on the Forgiveness Scale, and Table (6) shows this(see table 6)

Table (6) shows that the mean of the Forgiveness of the study subjects from the males groups on the Forgiveness Scale / Subscale $(2.69,2.52,2.44,2.55)$, and from females groups $(2.68,2.32,2.43,2.48)$. This indicates that there are apparent differences in the Forgiveness averages on the Forgiveness Scale / Subscale between males and females. To find out the significance of these differences, t-test for independent samples was performed. Table (7) shows these results(see table 7).

It is noted from table (7) that the values of t-test between means of males and females groups on the Forgiveness Scale and Subscales (Forgiveness of Self and Forgiveness of Situations) is not statistically significant at the level $(\alpha=0.05)$,thus accept the null hypothesis that: there aren't statistically significant differences at the level $(\alpha=0.05)$ in forgiveness of Syrian refugee's students in Jordan that can be attributed to the student's gender (males and females). but the value of t-test between means of males and females on Subscale (Forgiveness of Others) is statistically significant at the level $(\alpha=0.05)$, thus rejecting the null hypothesis and acceptance of alternative, that there are statistically significant differences at the level $(\alpha=0.05)$ between the average grades of students is attributable to student's gender, i.e., the level of Forgiveness of Others of males Syrian refugee's students in Jordan is Higher than level of Forgiveness of Others of females.

2. The results of the second hypothesis test: There will be no statistically significant differences $(\alpha=0.05)$ in forgiveness of Syrian refugee's students in Jordan that can be attributed to the student's developmental stage.

In order to test the hypothesis, the averages and standard deviations of early adolescents and middle adolescents groups were extracted on the Forgiveness Scale, and Table (8) shows this.(see table 8).

Table (8) shows that the mean of the Forgiveness of the study subjects from the early adolescents groups on the Forgiveness Scale / Subscale $(2.67,2.40,2.41,2.49)$, and from middle adolescents groups $(2.74,2.51,2.55,2.60)$. This indicates that there are apparent differences in the Forgiveness averages on the Forgiveness Scale / Subscale between early and middle adolescents. To find out the significance of these differences, $t$-test for independent samples was performed. Table (9) shows these results (see table 9)

It is noted from table (9) that the values of t-test between means of early and middle adolescents on the Forgiveness Scale and Subscales is not statistically significant at the level $(\alpha=0.05)$, thus accept the null hypothesis that: there aren't statistically significant difference sat the level $(\alpha=0.05)$ in forgiveness of Syrian refugee's students in Jordan that can be attributed to the student's developmental stage.

\section{Discussion}

This Part will includes a discussion of the findings of the study according to the sequence of its questions. First question: What is the level of forgiveness of Syrian refugee's students in Jordan?

The results showed that the level of forgiveness was moderate on (HFS) scale and Subscales, and its averages in descending order: Forgiveness of Self, Forgiveness of Situations, and Forgiveness of Others. This results contrast with Abdullah study (2011), Moheisen and Halhul (2012) where students in Iraq are characterized as a low level of Forgiveness, but students in Gaza are characterized as high level of Forgiveness.

This level of Forgiveness can be explained by the ecological niche of personal attributes and interactions with the environment which lead to the full realisation of the individual's potential (Sontag, 1996). The bio-ecological theory gives a detailed explanation of the situation, possible causes, and explains how the solutions implemented in different contexts may benefit Syrian Students in Jordan(Rosa and Tudge, 2013), ie the quality of welfare and social and psychological integration programs provided to Syrian refugee's students in Jordan which supervised and implemented by UNICEF and their partners such as Save the Children Association.

Second question: Are there any statistically significant differences in forgiveness of Syrian refugee's students in Jordan that can be attributed to the student's gender and his developmental stages? 
There aren't statistically significant differences in (HFS) scale/Subscales: Self Forgiveness \& Situations Forgiveness due to: student gender, and developmental stage, While differences in Forgiveness of Others statistically significant for males. This result is corresponded with Abdullah (2011),Zuhairi (2013),\& contradict with Moheisen and Alhalloul (2012).

There aren't statistically significant differences in forgiveness of Syrian refugee's students in Jordan attributed to the student's developmental stage. This finding seems logical because the study sample targeted adolescent children who had the same contexts.

\section{Recommendations}

1. Making more studies on the impact of displacement due to wars, crises and disasters at levels of unforgiveness for displaced populations in different developmental stages.

2. Invest the results of this study in developing psychological and social care programs about Syrian refugee's students in Jordan and other countries.

3. Include courses of forgiveness with others in educational programs.

\section{References}

- Abdullah ,F. (2011) Social forgiveness and its relation to specialization and gender and Parents treatment among students of the University of Baghdad. Journal of Educational and Psychological research ,(28),p(256-275).

-Affouneh, S. (2007). How sustained conflict makes moral education impossible: Some observations from Palestine. Journal of Moral Education,36(3), 343-356.

-Alliance News. (2013). France urges action on Syria, says 120,000 dead. (2013, September 25) New York: Morning Star.

- American Psychological Association, 2006. Permission is granted to reproduce 4rand distribute fully or in part at no charge provided the following citation is included: merican Psychological Association, (2006). Forgiveness: A Sampling of Research Results. Washington, DC: Office of International Affairs. Reprinted, 2008 .

- Araujo, D. \& Davids, K. (2009). Ecological approaches to cognition and action in sport and exercise: Ask not only what you do, but where you do it. International Journal of Sport Psychology, 40, p. 144-151.

- Bronfenbrenner, U. (1994). Ecological models of human development. In International encyclopedia of education, 13, p.1643-1647.

- Bronfenbrenner, U. \& Ceci, S.J. (1994). Nature-Nature reconceptualised in developmental perspective: A Bioecological model. Psychological Review, 101 (4): 568-586.

- Bronfenbrenner, U. \& Evans, G.W. (2000). Developmental sciences in the 21 st century: merging questions, theoretical models, research designs and empirical findings. Social Development, 9 (1), p. 115-125.

-Darling, N. 2007. Ecological Systems Theory: The Person in the Center of the Circles. Research in Human Development, 4 (3-4),p. 203-217.

-Donald, D. Lazarus, S. \& Lolwana, P. (2006). Educational psychology in social Context. Cape Town: Oxford University Press.

-Eggen, P. \& Kauchak, D. (2010).Educational Psychology: Windows to the classrooms. New Jersey: Pearson Education.

-Evans, R., Garner, P., \&Honig, A. S. (2014). Protection against violence, abuse and neglect in early childhood: A review of the literature on research, policy and neglect-special issue. Early child development and care(pp. 1-65).New York: UNICEF.

-Fernández-Capo, M., Fernández, S. R., Sanfeliu, M. G., Benito, J. G., \& Worthington, E. L., Jr. (2017). Measuring forgiveness: A systematic review. European Psychologist, 22(4), 247-262.

-George,A. (2011), Journal of Human Behavior in the Social Environment, 21:4,423 437,Department of Social Work, Arkansas State University, State University, Arkansas, USA.

-Luskin, F. (2002).Forgive for good: A proven prescription for health and happiness. San Francisco, CA: Harper.

- María Prieto-Ursúa, Rafael Jódar, Elena Gismero-Gonzalez, Maria José Carrasco, Maria Pilar Martínez \& Virginia Cagigal (2018) Conditional or Unconditional Forgiveness? An Instrument to Measure the Conditionality of Forgiveness, The International Journal for the Psychology of Religion, 28:3, 206222, DOI: $10.1080 / 10508619.2018 .1485829$

- McMillan, B.W. (1990). An ecological perspective on individual human development.Early Child Development and Care, 55: 33-42.

- Moheisen,O. Halhul ,I .(2012) Forgiveness and its relation to psychological health among students of Alaqsa university. Arab journal for psychological sciences , (8),32-33

-Rosa, E.M. \& Tudge, J. 2013. Urie Bronfenbrenner's theory of human development: Its evolution from ecology to bioecology. Journal of Family Theory \& Review, 5, p. 243-258.

-Sharp, J., \& Blanchard, C. (2013). Armed conflict in Syria: U.S. and International Response ,Congressional 
Research Service. (CRS Publication No. 7-5700).

-Sontag, J.C. 1996. Towards a comprehensive theoretical approaches for disability research: Bronfenbrenner revisited. Journal of Special Education, 30(1), p. 319-344

-Tudge, J. R. H., Mokrova, I. L., Hatfield, B. E.,\& Karnik, R. B. (2009). Uses and misuses of Bronfenbrenner's bio-ecological theory of human development.Journal of Family Theory and Review, 1, p. 198-210.

-Washington, DC: US Government Printing Office. Retrieved from http: //fpc.state.gov/documents/organization/208164.

-Worthington, E. L., \& Wade, N. G. (1999). The social psychology of unforgiveness and forgiveness and implications for clinical practice. Journal of Social and Clinical Psychology, 18, 385-418.

- Al-Zaroo, S., \&Hundt, G. L. (2003). Education in the context of conflict and instability: The Palestinian case.Social Policy \&Administration37(2), 165-180.

- Zuhairi , M.(2013). Moral intelligence and its relation to social forgiveness among middle school students , Educational studies , 6(21),9-38.

Tables

Table (1) Distribution of Study Sample

\begin{tabular}{ccccc}
\hline Variables & Variable levels & Frequency & Percent \\
\hline \multirow{2}{*}{ Gender } & & Male & 95 & 49.2 \\
& & Female & 98 & 50.8 \\
& \multirow{3}{*}{ Total } & & 193 & $100 \%$ \\
& & & 154 & 79.8 \\
& & Early adolescence & 39 & 20.2 \\
& \multirow{2}{*}{ Total } & middle adolescence & 193 & $100 \%$ \\
\hline
\end{tabular}

Table (2): The Discrimination indices (correlation coefficient) for the Forgiveness Scale

\begin{tabular}{lllllllll}
\hline & \multicolumn{2}{l}{ Self Forgiveness } & \multicolumn{3}{l}{ Forgiveness of Others } & \multicolumn{3}{c}{ Forgiveness of Situations } \\
\hline Item & $\begin{array}{l}\text { correlation } \\
\text { with } \\
\text { Subscale }\end{array}$ & $\begin{array}{l}\text { correlation } \\
\text { with Total }\end{array}$ & Item & $\begin{array}{l}\text { correlation } \\
\text { with } \\
\text { Subscale }\end{array}$ & $\begin{array}{l}\text { correlation } \\
\text { with Total }\end{array}$ & $\begin{array}{l}\text { correlation } \\
\text { Item } \\
\text { Subscale }\end{array}$ & $\begin{array}{l}\text { correlation } \\
\text { with Total }\end{array}$ \\
\hline 1 & $0.517^{* *}$ & $0.337^{* *}$ & 7 & $0.500^{* *}$ & $0.266^{* *}$ & 13 & $0.385^{* *}$ & $0.470^{* *}$ \\
2 & $0.601^{* *}$ & $0.390^{* *}$ & 8 & $0.404^{* *}$ & $0.295^{* *}$ & 14 & $0.717^{* *}$ & $0.476^{* *}$ \\
3 & $0.443^{* *}$ & $0.207^{* *}$ & 9 & $0.490^{* *}$ & $0.302^{* *}$ & 15 & $0.345^{* *}$ & $0.315^{* *}$ \\
4 & $0.529^{* *}$ & $0.385^{* *}$ & 10 & $0.272^{* *}$ & $0.271^{* *}$ & 16 & $0.488^{* *}$ & $0.377^{* *}$ \\
5 & $0.471^{* *}$ & $0.319^{* *}$ & 11 & $0.584^{* *}$ & $0.350^{* *}$ & 17 & $0.373^{* *}$ & $0.348^{* *}$ \\
6 & $0.600^{* *}$ & $0.462^{* *}$ & 12 & $0.485^{* *}$ & $0.431^{* *}$ & 18 & $0.357^{* *}$ & $0.250^{* *}$ \\
\hline
\end{tabular}

The Discrimination indices for all Items of Forgiveness Scale in table (2) was found greater than (0.25) and it is sig at (0.05) and acceptable values.

Table (3): The factor analysis for the Forgiveness Scale

\begin{tabular}{|c|c|c|c|c|c|c|}
\hline \multirow{3}{*}{ Component } & \multicolumn{3}{|c|}{ Initial Eigen values } & \multirow{2}{*}{\multicolumn{2}{|c|}{$\begin{array}{l}\text { Extraction Sums of Squared } \\
\text { Loadings }\end{array}$}} & \multirow{3}{*}{ Cumulative $\%$} \\
\hline & & & \multirow[b]{2}{*}{ Cumulative \% } & & & \\
\hline & Total & Variance & & Total & $\%$ of Variance & \\
\hline 1 & 6.745 & 37.471 & 37.471 & 6.745 & 37.471 & 37.471 \\
\hline 2 & 3.164 & 17.578 & 55.048 & 3.164 & 17.578 & 55.048 \\
\hline 3 & 2.631 & 14.617 & 69.665 & 2.631 & 14.617 & 69.665 \\
\hline 4 & 2.404 & 13.357 & 83.022 & 2.404 & 13.357 & 83.022 \\
\hline 5 & 1.202 & 6.676 & 89.698 & 1.202 & 6.676 & 89.698 \\
\hline
\end{tabular}

Table (4): The Internal consistency reliability of Forgiveness Scale

\begin{tabular}{|l|l|l|}
\hline Forgiveness Scale / Subscale & Cranach's alpha & split half \\
\hline Forgiveness of Self & 0.816 & 0.844 \\
\hline Forgiveness of Others & 0.761 & 0.796 \\
\hline Forgiveness of Situations & 0.595 & 0.692 \\
\hline Total Forgiveness & 0.764 & 0.721 \\
\hline
\end{tabular}


Table (5): Averages and Standard deviations of Forgiveness Scale / Subscale

\begin{tabular}{|c|c|c|c|c|c|}
\hline $\begin{array}{l}\text { Items } \\
\text { Order }\end{array}$ & Forgiveness items / Subscale & N Mean & SD & $\begin{array}{l}\text { Std. } \\
\text { Error }\end{array}$ & Interpretation \\
\hline 5 & $\begin{array}{l}\text { With time I am understanding of myself for mistakes } 1 \\
\text { I've made. }\end{array}$ & 1933.235 & 1.015 & 0.074 & High \\
\hline 3 & $\begin{array}{l}\text { Learning from bad things that I've done helps me get } 1 \\
\text { over them. }\end{array}$ & 1933.115 & 1.035 & 0.075 & High \\
\hline 1 & $\begin{array}{l}\text { Although I feel bad at first when I mess up, over time I1 } \\
\text { can give myself some slack. }\end{array}$ & 1932.759 & 1.033 & 0.075 & Medium \\
\hline 6 & $\begin{array}{l}\text { I don't stop criticizing myself for negative things I've } 1 \\
\text { felt, thought, said, or done. }\end{array}$ & 1932.416 & 1.059 & 0.077 & Medium \\
\hline 4 & $\begin{array}{l}\text { It is really hard for me to accept myself once I've } 1 \\
\text { messed up. }\end{array}$ & 1932.415 & 1.007 & 0.073 & Medium \\
\hline 2 & $\begin{array}{l}\text { I hold grudges against myself for negative things I've } 1 \\
\text { done. }\end{array}$ & 1932.195 & 1.054 & 0.076 & Medium \\
\hline \multicolumn{2}{|c|}{ Forgiveness of Self } & 1932.685 & 0.526 & 0.038 & Medium \\
\hline 14 & $\begin{array}{l}\text { With time I can be understanding of bad circumstances } \\
\text { in my life. }\end{array}$ & 1932.886 & 0.919 & 0.068 & Medium \\
\hline 18 & $\begin{array}{l}\text { Eventually I let go of negative thoughts about bad } \\
\text { circumstances that are beyond anyone's control. }\end{array}$ & 1932.652 & 1.017 & 0.074 & Medium \\
\hline 16 & I eventually make peace with bad situations in my life. 1 & 1932.484 & 1.036 & 0.076 & Medium \\
\hline 13 & $\begin{array}{l}\text { When things go wrong for reasons that can't be } \\
\text { controlled, I get stuck in negative thoughts about it. }\end{array}$ & 1932.309 & 1.153 & 0.083 & Medium \\
\hline 17 & $\begin{array}{l}\text { It's really hard for me to accept negative situations that } \\
\text { aren't anybody's fault. }\end{array}$ & 1932.243 & 1.113 & 0.081 & Medium \\
\hline 15 & $\begin{array}{l}\text { If I am disappointed by uncontrollable circumstances in } \\
\text { my life, I continue to think negatively about them. }\end{array}$ & 1932.085 & 1.020 & 0.074 & Medium \\
\hline \multicolumn{2}{|c|}{ Forgiveness of Situations } & 1932.436 & 0.540 & $\mathbf{0 . 0 3 9}$ & Medium \\
\hline 8 & $\begin{array}{l}\text { With time I am understanding of others for the mistakes } \\
\text { they've made. }\end{array}$ & 1933.073 & 0.965 & 0.070 & High \\
\hline 12 & $\begin{array}{l}\text { When someone disappoints me, I can eventually move } \\
\text { past it. }\end{array}$ & 1932.568 & 1.010 & 0.073 & Medium \\
\hline $\begin{array}{l}\text { Items } \\
\text { Order }\end{array}$ & Forgiveness Scale / Subscale & N Mean & SD & $\begin{array}{l}\text { Std. } \\
\text { Error }\end{array}$ & Interpretation \\
\hline 10 & $\begin{array}{l}\text { Although others have hurt me in the past, I have } \\
\text { eventually been able to see them as good people. }\end{array}$ & 1932.550 & 1.074 & 0.078 & Medium \\
\hline 11 & If others mistreat me, I continue to think badly of them. 1 & 1932.235 & 1.126 & 0.082 & Medium \\
\hline 9 & I continue to be hard on others who have hurt me. & 1932.073 & 1.049 & 0.076 & Medium \\
\hline 7 & $\begin{array}{l}\text { I continue to punish a person who has done something } \\
\text { that I think is wrong. }\end{array}$ & 1932.000 & 1.051 & 0.076 & Medium \\
\hline \multicolumn{2}{|c|}{ Forgiveness of Others } & 1932.418 & 0.488 & 0.035 & Medium \\
\hline \multicolumn{2}{|c|}{ Total Forgiveness } & 1932.514 & 0.380 & 0.027 & Medium \\
\hline
\end{tabular}

Table (6): Averages and Standard deviations of males and females groups on the Forgiveness Scale / Subscale

\begin{tabular}{|l|l|l|l|l|l|}
\hline Forgiveness Scale / Subscale & Gender & N & Mean & SD & Std. Error \\
\hline \multirow{2}{*}{ Forgiveness of Self } & Male & 95 & 2.69 & 0.54 & 0.06 \\
\cline { 2 - 6 } & Female & 98 & 2.68 & 0.51 & 0.05 \\
\hline \multirow{2}{*}{ Forgiveness of Others } & Male & 95 & 2.52 & 0.49 & 0.05 \\
\cline { 2 - 6 } & Female & 98 & 2.32 & 0.47 & 0.05 \\
\hline \multirow{2}{*}{ Forgiveness of Situations } & Male & 95 & 2.44 & 0.52 & 0.05 \\
\cline { 2 - 6 } & Female & 98 & 2.43 & 0.56 & 0.06 \\
\hline \multirow{2}{*}{ Total Forgiveness } & Male & 95 & 2.55 & 0.36 & 0.04 \\
\cline { 2 - 6 } & Female & 98 & 2.48 & 0.39 & 0.04 \\
\hline
\end{tabular}


Table (7): t-test between means of males and females groups on the Forgiveness Scale / Subscale

\begin{tabular}{|l|l|l|l|l|l|}
\hline Forgiveness Scale / Subscale & Levene's Test for Equality of Variances & \multicolumn{2}{l|}{ t-test for Equality of Means } \\
\hline & F & Sig. & t & Df & Sig \\
\hline Forgiveness of Self & 0.009 & 0.925 & 0.199 & 191 & 0.843 \\
\hline Forgiveness of Others & 0.157 & 0.693 & 2.817 & 191 & $0.005^{*}$ \\
\hline Forgiveness of Situations & 0.334 & 0.564 & 0.087 & 191 & 0.930 \\
\hline Total Forgiveness & 0.040 & 0.841 & 1.284 & 191 & 0.201 \\
\hline
\end{tabular}

* statistically significant at the level of $(\alpha=0.05)$

Table (8): Averages and Standard deviations of early adolescents and middle adolescents groups on the Forgiveness Scale / Subscale

\begin{tabular}{|l|l|l|l|l|l|}
\hline Forgiveness Scale / Subscale & developmental stage & N & Mean & SD & Std. Error \\
\hline \multirow{2}{*}{ Forgiveness of Self } & early adolescents & 154 & 2.67 & 0.51 & 0.04 \\
\cline { 2 - 6 } & middle adolescents & 39 & 2.74 & 0.58 & 0.09 \\
\hline \multirow{2}{*}{ Forgiveness of Others } & early adolescents & 154 & 2.40 & 0.47 & 0.04 \\
\cline { 2 - 6 } & middle adolescents & 39 & 2.51 & 0.55 & 0.09 \\
\hline \multirow{2}{*}{ Forgiveness of Situations } & early adolescents & 154 & 2.41 & 0.53 & 0.04 \\
\cline { 2 - 6 } & middle adolescents & 39 & 2.55 & 0.56 & 0.09 \\
\hline \multirow{2}{*}{ Total Forgiveness } & early adolescents & 154 & 2.49 & 0.37 & 0.03 \\
\cline { 2 - 6 } & middle adolescents & 39 & 2.60 & 0.42 & 0.07 \\
\hline
\end{tabular}

Table (9): t-test between means of early and middle adolescents groups on the Forgiveness Scale / Subscale

\begin{tabular}{|l|l|l|l|l|l|}
\hline Forgiveness Scale / Subscale & Levene's Test for Equality of Variances & \multicolumn{4}{l|}{ t-test for Equality of Means } \\
\hline & F & Sig. & t & Df & Sig \\
\hline Forgiveness of Self & 1.399 & 0.238 & 0.739 & 191 & 0.461 \\
\hline Forgiveness of Others & 0.759 & 0.385 & 1.286 & 191 & 0.200 \\
\hline Forgiveness of Situations & 0.154 & 0.695 & 1.532 & 191 & 0.127 \\
\hline Total Forgiveness & 1.171 & 0.281 & 1.589 & 191 & 0.114 \\
\hline
\end{tabular}

Figure 1: components \& Eigen value of Forgiveness Scale

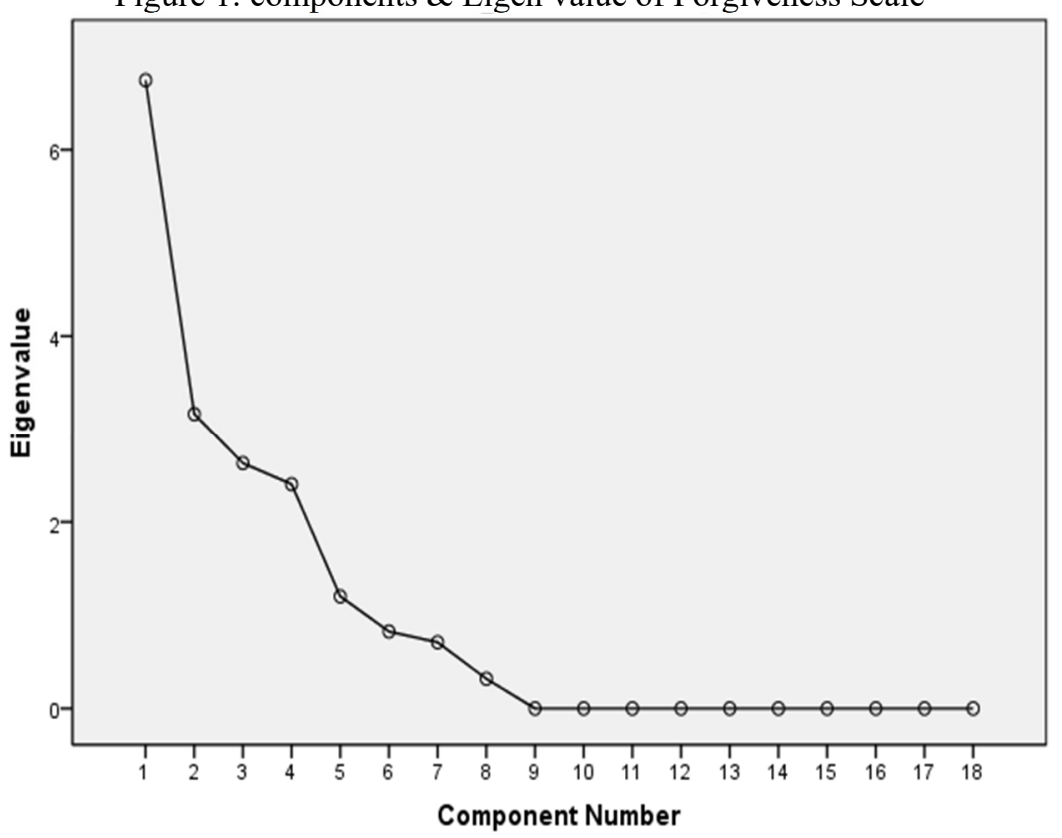

